\title{
Dangerous Citizens Online: a case study of an author-press-library partnership
}

\author{
REBECCA KENNISON \\ Director, Center for Digital Research and Scholarship \\ Columbia University Libraries/Information Services \\ New York, USA \\ NENI PANOURGIÁ \\ Associate Professor, Department of Anthropology \\ Columbia University \\ New York, USA \\ HELEN TARTAR \\ Editorial Director \\ Fordham University Press \\ New York, USA
}

This essay traces how Neni Panourgiá, Professor of Anthropology at Columbia University, Fordham University Press and the Columbia Center for Digital Research and Scholarship worked together to produce an online book that strives not to replace but to augment the printed book it accompanies. The 'synaesthetic' reading experience provided by the online book enables readers to experience more fully the author's rich fieldwork materials and to customize their own reading of the various texts that make up the book, thereby gaining a better sense of the multiple levels of anthropological analysis. Moreover, the online book can remain open-ended, enabling ongoing updating. Particular attention is devoted to the challenges faced by the digital project and the aspects of the partnership that made the project a success.

\section{The partners and the project}

Sometimes the best collaborations come about as the result of chance or happy circumstance. That was true of the impetus for the project that would become Dangerous Citizens Online. ${ }^{1}$ Late in October 2008, two of us - Helen Tartar and Rebecca Kennison - met in Rebecca's office to discuss the talk Rebecca had invited Helen to give as part of a panel entitled 'Future of the Book: Can the Endangered Monograph Survive?'2 With the future of the book very much on our minds, we turned at the end of that conversation to the possibility of Fordham University Press and Columbia University Libraries' Center for Digital Research and Scholarship (CDRS) working together on a project involving a Columbia author that would lend itself well to online treatment. Helen thought for a moment, then exclaimed, "Have I got the book for you!". She explained that Fordham was wrestling with the manuscript of Dangerous Citizens: The Greek Left and the Terror of the State, by an anthropology professor at Columbia, Neni Panourgiá. Neni wanted her reader to be able to put together a composite reading experience. To that end, she had written the book as a main text accompanied by 'shadow texts', which she named 'parerga'. ${ }^{3}$ Helen and Neni had discussed various possible ways to present these simultaneously, but the simple fact was that they had not been written with an eye to the physical constraints of a printed page - at one point, more than ten pages of parerga corresponded to three lines of main text. Moreover, Neni was exceptionally sensitive to the mediatic 
diversity of her fieldwork material - not only to the widely different types of text she drew upon, each of whose physical form gave clues about its significance and history, and not just to the difference between oral and written sources. Her material actively included songs, photographs, videos and various physical objects. Neni had asked about the possibility of creating a DVD to accompany the book, on which she would be able to expand the level of representation of her field material by creating what she calls a 'synaesthetic experience' of reading: presenting live interviews, clips from musical and theatrical performances, portions of documentaries and a timeline. Helen had concluded that a DVD would not be possible the one time Fordham had tried anything like this before, the author had provided an enormous subsidy. Would an online rendering work better, we wondered?

Even before the first meeting of all the partners in December 2008, Fordham had provided the CDRS team with unedited files so that they could begin to understand the complexity of the text. The copy-edited files, image files and final print book design were delivered in February 2009, and the final InDesign files and images were supplied in June. Knowing that to provide maximum flexibility in the online implementation they would need the book tagged in XML, the CDRS team sent these final files out to an XML vendor, Charlesworth China $^{4}$, who completed the work in October.

Throughout the summer of 2009, CDRS discussed the project and the desired functionality at length. September 2009 saw the beginning of active development. Following Agile software development methodology, which focuses on iterative development, the CDRS team broke the design and functionality development into short projects ('sprints') that could be done in just a few days, with weekly review and discussion, resulting in further quick rounds of development in response to feedback.

By the end of October, the team at CDRS finally felt they had something tangible enough to show to the other partners and to other users. At the beginning of November they ran several focus groups, including one with Neni's students, to elicit user feedback. As a result of the feedback from both partners and potential users, they rethought much of what they had done to that point, especially the way that the parerga opened in the margins of the online page. The CDRS team went into overdrive, knowing they and the press were scheduled to demonstrate the website at the American Anthropological Association's annual meeting at the beginning of December. Although some final - and vital - components (such as the maps section and an interactive timeline) were not ready for the launch, in the finest online tradition of beta releases, the project nevertheless went live on 2 December 2009.

\section{The challenges}

While the three partners in the project - the author, the publisher, and the online development group worked extraordinarily well together in a way that we believe could provide a model for other groups, we encountered several challenges as we tried to turn the static pages of the print book into the interactive pages of the online project.

The first of these was addressing Fordham's initial concerns: copyright ownership, the primacy of version and the possibility that a book made freely available online might adversely affect print sales. We carefully worked through these issues until all of us felt comfortable with the decisions. For copyright ownership, we agreed to balance user experience with copyright protections. For the print books, all rights are held by Fordham, with the exception of images, which remain with the original copyright owner. For the online version, we decided to put the entire book under a Creative Commons Attribution-Noncommercial-No Derivative Works license ${ }^{5}$, with the understanding that in the future some content might be licensed under some other term. We determined that both formats had equal value and so aggressively cross-marketed them, selling the print book from the online site and linking to the online site from the homepage of the book on the Fordham University Press site.

A second substantive challenge was to design the online site in accordance with web accessibility best practices, such as semantically meaningful HTML (e.g., links and image text that can be read out loud by a screen reader), color palettes and differentiated links that take into account the color blind, design and functionality that allow those who cannot or do not use a mouse to navigate the site nevertheless, text-sizing controls for those who might be visually challenged, etc. Learning and implementing these best practices was a sometimes steep learning curve for the CDRS team, but 
the end result was a site that works well for most users, including those on mobile phones. Although mobile phone use has so far resulted in less than $2 \%$ of visitors to the site, the fact that the site functions well on such devices is a particular point of pride for the development team.

As in the print book, the biggest challenge in design and implementation was how to properly display the parerga to enable the user experience Neni had originally envisioned and how within that framework to differentiate footnotes and citations from parerga so that users would know what kind of material they were encountering. We hit on the idea of an icon for each type of material that a user might encounter - audio, image, parergon text, or video. When the user clicks on the icon, the associated material shows up in the margin alongside the main text. Footnotes appear as asterisks; citations as clickable links from author-date forms in the main text, parerga, or footnotes.

The final challenge - and one not yet resolved was how to allow Neni to add new material at will and to provide users with various ways to interact both with the text and with her. In the next year the CDRS team will develop additional functionality to solve these problems: an interactive chronology and interactive maps, a user annotation feature similar to Google's SideWiki, author editing tools and a mechanism for commenting.

\section{Online book, not book online - What's the difference?}

Perhaps the greatest challenge was a conceptual one, that of thinking of Dangerous Citizens as not a book online but as an online book. There have been many books online, from e-books to experiments such as Gutenberg-e ${ }^{6}$. As Rebecca observed in a blog posting in August 20097, what makes all of these books online instead of online books is that they are readily recognizable as books. We were instead striving with this project to create an online book, one that was designed with three principles in mind: 1) users discover and then interact with online material differently from how they explore and interact with print; 2) an online book has a continuing life; and 3) an online book, since it is not a static text, must adapt to evolving technologies and thus ensure ongoing access.
Addressing the first principle, Dangerous Citizens Online was designed to allow anyone who found any page via any search engine to be clear as to navigation on the site; we provide a variety of methods to navigate the site, from the traditional table of contents to interactive maps and chronologies. Second, while the original text of the online book was identical to that of the print book, this was only the starting place for the online version. The images online are in color, and more can be added, as can audio and video and additional text, as Neni chooses. There will be wiki for definitions, place histories and annotations. Content can be in any language, with any number of translations. Educational content can be developed and added. Users can become involved, both through contact with Neni and by providing content of their own that may make its way onto the site. Finally, because CDRS built the book leveraging XML and XSLT, we can easily add and update content, migrate the content at will and archive it for the long term.

\section{Successes so far}

By most measures, Dangerous Citizens Online has been a success. Once we had decided on the domain name for the site (dangerouscitizens. columbia.edu), we launched a blog in April 2009, using that domain to establish an online presence for the project; over the following months the blog described the philosophical underpinnings of the project and the work that was being done on the site and included entries written by each of the partners. This approach allowed us to develop a following and to link to the site in all of our marketing materials, even though the book itself did not appear in print until September and online until December. As a result, the two book sites (Columbia's and Fordham's) continue to appear as the top two search engine results, ahead of even Amazon.

Between 1 December 2009 and 30 April 2010, Dangerous Citizens Online received 4,814 visits from 2,526 unique visitors from 83 countries. Visitors spent an average of 5 minutes 46 seconds on the site, looking at 28,485 pages (average: 5.92 pages per visit). According to Google Analytics' benchmarking report, arts and humanities sites of a similar size over the same period averaged 273 visits and 560 page views (2.05 pages per visit), 
with visitors spending only 27 seconds on average on the site. In comparison, those people who discover Dangerous Citizens Online spend considerable time reading and browsing, a testament both to the content and its user-friendly display.

This year Dangerous Citizens was awarded Honorable Mention in the category Archaeology and Anthropology of the PROSE Awards of the American Association of Presses.

\section{Model partnership}

What made this project successful? We believe it was the collective commitment of the three partners working together to make it so. While there have been a number of successful presslibrary collaborations and a plethora of ideas about what works and what does not ${ }^{8}$, we believe that our approach, actively involving the author, the author's publisher, and the author's institutional library, provides a compelling model for other press-library collaborations. Salient points of this partnership include the following:

- a focus on the author and the work rather than on a joint institutional mission (press-library) that very often does not directly include the author

- a shared vision, understanding and agreement as to the benefits for each of the three partners

- mutual respect for the products of the different partners and recognition of their different strengths and patterns of use - the website does not try to replace the printed book

- clearly defined responsibilities, utilizing each other's strengths and expertise

- shared cost burden (for Fordham and CDRS) and shared risk by all partners

- open and continuous communication

- a coordinated marketing effort.

Within this partnership, Neni has worked tirelessly to provide the original vision, text and images; to obtain proper permissions to publish images and lengthy quotations online; to create new text, new images and video; and to push the CDRS team to think creatively of ways to allow both her and those who encounter the work to interact with the online work and with each other.

Fordham brought to the project the initial peer review of the manuscript and the subsequent decision to publish the book, developmental editing, a print book design that provided a basis for thinking about how the online book should be both similar and different, copy-editing, proofreading, typesetting files that were used both for the print book and for the XML conversion, and considerable effort in marketing and sales.

CDRS brought to the partnership expertise in web publishing - especially in designing for various platforms and browsers, programming and XML/XSLT skills, and an understanding of online rights and permissions issues - as well as knowledge of usability and accessibility best practices, search engine optimization (SEO) and online marketing techniques.

The site that has resulted is an opportunity to explore the process of reading and be reminded of how many senses are involved in academic fieldwork. Moreover, at a time when various academic fields have found themselves in an environment of rapid developments (be they radical breakthroughs in developmental psychology or macroeconomics, or, as in anthropology, a matter of a rapidly changing world and the need to record these changes in a scholarly manner), an online book can allow an author to keep a project up to date without losing its original intellectual premises.

\section{References}

1. Dangerous Citizens Online:

http://dangerouscitizens.columbia.edu (accessed 18 April 2010).

2. Future of the Book: Can the Endangered Monograph Survive?:

http://scholcomm.columbia.edu/future-book-canendangered-monograph-survive (accessed 1 May 2010).

3. A Note on the Shadow Text (or Parerga): http://dangerouscitizens.columbia.edu/blog/2009/ 06/01/a-note-on-the-shadow-text-or-parerga/ (accessed 1 May 2010).

4. Charlesworth Group: http://www.charlesworth.com/ (accessed 1 May 2010).

5. Attribution-Noncommercial-No Derivative Works 3.0 Unported: http://creativecommons.org/licenses/by-ncnd/3.0/ (accessed 1 May 2010).

6. Much has been written about the Mellon-funded Gutenberg-e project: 
http://www.gutenberg-e.org/ (accessed 1 May 2010). Two overviews of the project include Manning, P, Gutenberg-e: Electronic Entry to the Historical Professoriate, The American Historical Review, 2004, 109(5), 1505-1526; Wittenberg, K, The Gutenberg-e Project: Opportunities and Challenges in Publishing Born-Digital Monographs, Learned Publishing, 2009, 21(1), 36-41.

7. A Book Online? No, An Online Book!:

http://dangerouscitizens.columbia.edu/blog/2009/ 08/24/online-books/ (accessed 1 May 2010).

8. See, for example, Case, M M, Partners in Knowledge Creation: An Expanded Role for Research Libraries in the Digital Future, Journal of Library Administration, 2008, 48(2), 141-156; Neal, $\mathrm{J} \mathrm{G}$, Symbiosis or Alienation: Advancing the University Press/Research Library Relationship Through Electronic Scholarly Communication, Journal of Library Administration, 2001, 35 (1/2), 5-18; Steele, C, Scholarly Monograph Publishing in the 21st Century: The Future More Than Ever Should Be an Open Book, Journal of Electronic Publishing, 2008,11(2):

http://dx.doi.org/10.3998/3336451.0011.201 (accessed 18 April 2010); Zalta, E, The Stanford Encyclopedia of Philosophy: A University/Library Partnership in Support of Scholarly Communication and Open Access, College \& Research Library News, 2006, 67(8), 502-504, 507.
Article (c) Rebecca Kennison, Neni Panourgiá and Helen Tartar

Rebecca Kennison

Director, Center for Digital Research and Scholarship Columbia University Libraries/Information Services

20 I Lehman Library

International Affairs Building

420 West II 8th Street

New York, New York 10027, USA

Tel.: + |-2 | 2-85 I-28 I 2

E-mail: rkennison@columbia.edu

Neni Panourgiá

Associate Professor, Department of Anthropology

Columbia University

452 Schermerhorn Extension

I 200 Amsterdam Avenue

New York, New York 10027, USA

E-mail:np255@columbia.edu

Helen Tartar

Editorial Director

Fordham University Press

2546 Belmont Avenue

Bronx, New York 10458, USA

E-mail: tartar@fordham.edu

To view the original copy of this article, published in Serials, click here:

http://serials.uksg.org/openurl.asp?genre=article\&issn=0953-0460\&volume=23\&issue=2\&spage=145

The DOI for this article is $10.1629 / 23145$. Click here to access via DOI:

http://dx.doi.org/10.1629/23145

For a link to the full table of contents for the issue of Serials in which this article first appeared, click here: http://serials.uksg.org/openurl.asp?genre=issue\&issn=0953-0460\&volume=23\&issue=2 